\title{
Studies on Learning Effects of AR-Assisted and PPT-Based Lectures
}

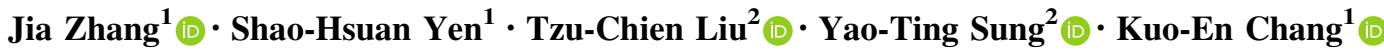

Published online: 14 September 2020

(C) The Author(s) 2020

\begin{abstract}
While common, computer presentations given during classroom lectures do not always improve learning effects; thus, this study incorporated three elements into technology-assisted classroom lectures: emphasis, augmentation, and integration. These three elements cannot be implemented simultaneously when using PowerPoint (PPT) presentations during classroom lectures. Therefore, the virtual and physical integration of augmented reality (AR) was employed to establish an assisted course lecturing tool for implementing these three elements. Teachers can refer to important content from textbooks (emphasis) while lecturing, and students can then use an AR device to scan the content and to call out related supplementary materials (augmentation) in facilitating their learning. These scanning and calling out functions of AR enable teachers to integrate technology-assisted tools with textbooks to enhance the effectiveness of classroom lectures. The pre- and posttest quasi-experimental research design
\end{abstract}

Kuo-En Chang

kchang@ntnu.edu.tw

Jia Zhang

zhangjia.tw@gmail.com

Shao-Hsuan Yen

snoopy19940614@gmail.com

Tzu-Chien Liu

tzuchien@ntnu.edu.tw

Yao-Ting Sung

sungtc@ntnu.edu.tw

1 Graduate Institute of Information and Computer Education, National Taiwan Normal University, 162, Heping East Road Section 1, Taipei, Taiwan

2 Department of Educational Psychology and Counseling, National Taiwan Normal University, Taipei, Taiwan was used to determine differences in the learning outcomes of two groups of AR-assisted and PPT-based course lectures. The experimental results indicate that the AR-assisted lecture was significantly more effective than the PPT-based lecture, and a similar result was obtained from a delayed test. According to interviews held with students, during the AR-assisted lecture, the students tended to focus on only one teaching medium and on the textbook content. By contrast, students of the PPT-based lecture became distracted while focusing on two different media sources simultaneously, resulting in the textbook content often being neglected.

Keywords Augmented reality - Educational technology · PPT-based lecture

\section{Introduction}

Presentation software is widely used in education and particularly in classroom lectures (James et al. 2006; Mantei 2000; Williams and Eggert 2002). Comparative studies on the effectiveness of computer presentations versus chalk and talk methods have drawn numerous conclusions over many years of discussion. The findings suggest that most teachers and students prefer the use of PowerPoint (PPT) presentations in classroom lectures (Jordan and Papp 2014; Rickman and Grudzinski 2000; Hill et al. 2012). Students prefer computer presentations over chalk and talk methods given the diverse forms of multimedia used in PPT presentations (Akhlaghi and Zareian 2015; Apperson et al. 2006; Hill et al. 2012; Savoy et al. 2009; Ledbetter and Finn 2018; Seth et al. 2010). However, inconsistent results have been obtained regarding the best means of achieving better learning outcomes. 
Some studies have demonstrated that computer presentations are more effective than chalk and talk methods (Dean et al. 2016; Jalali and Talebi 2014; Lowry 1999), whereas others have been unable to verify that superior learning outcomes are obtained through computer presentations (Bamne and Bamne 2016; Barlett and Strough 2003; Nouri and Shahid 2005; Pros et al. 2013; Sugahara and Boland 2006; Waheeda and Murthy 2015). To explore this inconsistency, researchers have used literature reviews and have performed meta-analyses. Shapiro et al. (2006) and Levasseur and Sawyer (2006) reviewed the benefits of computer presentations, while Baker et al. (2018) selected 48 research papers from the literature and conducted a meta-analysis to identify the benefits of computer presentations, obtaining the most recent research results.

Baker et al. (2018) revealed that although computer presentation teaching can improve students' affection (Ledbetter and Finn 2018), motivation (Szabo and Hastings 2000), and interest levels (Hill et al. 2012), it does not affect learning outcomes. In addition, Baker et al. (2018) suggested that PPTs used in classroom lectures must be designed in accordance with the cognitive theory of multimedia learning (Mayer 2001; Mayer and Moreno 2002) if cognitive load is to be prevented during learning. Increasing students' levels of interaction and attention during the teaching process was also recommended.

Jordan and Papp (2014) maintained that using PPTbased lectures excites students' attention but that students as a result become less focused on textbooks (Ahmadi et al. 2007). This leaves fewer opportunities for students to interact with teaching materials, resulting in no improvement in learning effects. Furthermore, Hill et al. (2012) noted that students may miss essential content from a textbook when they focus on the content of a computer presentation.

Numerous researchers have recently proposed principles for the design of effective presentations for improving the learning outcomes of computer presentation teaching, and the effects of these principles have been verified (Bartsch and Cobern 2003; Berk 2011; Berney and Betrancourt 2016; Gier and Kreiner 2009; Hallett and Faria 2006; Hallewell and Lackovic 2017; Johnson and Christensen 2011; Kim 2018; Miller and James 2011; Schnettler 2006; Tangen et al. 2011; Valdez 2013; Wecker 2012). Penciner (2013) proposed that when a teaching presentation is based on the cognitive theory of multimedia learning, two aspects can strengthen the effectiveness of technology-assisted classroom lectures: emphasis and augmentation. When using Penciner's design, the points that students should focus on are emphasized, and related augmented supplementary materials are provided.

Debevec et al. (2006) investigated the effects of different combinations of technology-assisted and physical classroom lectures (chalk and talk) on learning outcomes and found the use of both technology-assisted and physical classroom lectures to result in superior outcomes than the use of either single approach. To enhance interactions with and attention to computerized supplementary and textbook materials (Jordan and Papp 2014), teachers should integrate technologies with textbook use in developing classroom lectures. However, the three intensive teaching elements of emphasis, augmentation, and integration are impossible to employ simultaneously when providing a PPT presentation during a classroom lecture. Therefore, virtual and physical integration functions of augmented reality (AR) can be used to incorporate these three elements and to assist teachers in delivering classroom lectures.

Since the 1990s, various applications of AR have been developed; however, due to equipment-related limitations, its development has not been popularized. In recent years, as mobile technologies have become ubiquitous, education researchers have developed numerous applications of AR based on such technologies (Chang et al. 2014, 2015, 2018; Chang and Huang 2018; Chao et al. 2014, 2016; Gervautz and Schmalstieg 2012; Hsiao et al. 2013; Ibáñez and Carlos 2018; Zhang et al. 2014). One of these applications involves using an AR function to provide and superimpose virtual information of supplementary teaching materials over textbook content. For instance, Huang et al. (2016) used AR technologies to combine virtual information and textbook content to help learners gradually read through textbooks and corresponding supplementary materials. Zhang et al. (2015) built an AR system to assist teachers with curriculum instruction using virtual supplementary content. Cheng and Tsai (2014) used AR to convert artwork from storybooks into 3D images or dynamic videos to enhance interest in reading and to present abstract concepts illustrated in storybooks with simple images to reduce the complexity of learning materials. Ibáñez et al. (2014) used AR to present abstract concepts of electromagnetism in the form of superimposed 3D-simulated circuit diagrams to improve the learning outcomes of high school students. Chang et al. (in press) used a model of augmented 3D characters to enable students to perform practice exercises and to make observations to understand explanations of motor skills given in textbooks. The above AR applications involved learners using handheld devices to scan textbook content to reveal superimposed supplementary materials. This combined use of textbooks and virtual information exemplifies the three intensive teaching elements.

Emphasis, augmentation, and integration are implemented through the use of a combination of textbooks and virtual information. During classroom lectures, teachers can refer to the emphases from a textbook and draw the attention of their students. In addition, the students can read augmented supplementary materials of the specific 
emphasis when necessary. Under such circumstances, students can use AR devices to scan for emphases and to call out related supplementary materials, facilitating their learning. The scan and call out functions of AR devices enable teachers to integrate technology-assisted tools with textbooks, enhancing the benefits of technology-assisted classroom lectures.

Although the above studies integrated AR devices with textbooks, most were only concerned with students' learning and were not concerned with teachers' classroom lectures. Nonetheless, teachers often use PPTs in classroom lectures. Therefore, exploring the effectiveness of PPTs and AR devices integrated with textbooks and determining any differences in students' learning outcomes is necessary. This study involved developing an AR-assisted course lecturing tool with emphasis, augmentation, and integration features and applied the developed tool in classroom lectures for the elementary sixth grade to determine its effect on learning outcomes. Participants of the study were divided into two groups. Those in the control group were taught by teachers who used PPT presentations while those in the experimental group were taught with use of an AR mobile device designed to help students notice emphases and related augmentations. The experimental results indicate that the experimental group achieved more favorable posttest and delayed test scores than the control group. We also conducted interviews with students from both groups, and the results show that students from the experimental group preferred the use of AR mobile devices during lectures over not using such devices, and these students also exhibited a stronger learning concentration effect.

\section{AR-Assisted Lecturing}

The AR-assisted lecturing tool used in this study adopts the Streamlined Viewport Strategy System (SVSS) AR engine developed by Zhang et al. (2012). For this tool, students use handheld devices to scan textbook learning content; afterwards, supplementary materials are overlaid onto the learning content on the device screen for the students to view. This differs from PPT slide teaching, which uses another instructional medium to present supplementary material so that textbook learning content and supplementary materials are presented separately.

The lecturing steps of the AR-assisted tool involve the teacher first describing the concepts of each textbook learning item; the student then uses AR to scan the learning item and to read the supplementary material. After the student has completed learning activities associated with the current learning item, the teacher proceeds to describe concepts of the next learning item. The student then once again uses the handheld device to scan the textbook and to read the supplementary material. These process is repeated for each concept until a learning unit has been completed. In contrast, in PPT slide teaching, each item of textbook learning content is described by the teacher with computer slides, and the students then independently study the content of each slide.

Figure 1 illustrates lectures based on PPT slides and AR-assisted tools. Figures 2 and 3 illustrate two means of presenting supplementary materials. Figure 2 illustrates the separate presentation of textbook and supplementary materials during PPT-based lectures. Figure 3 illustrates how supplementary materials are overlaid onto a textbook during a lecture using AR-assisted tools.

\section{Experiment}

\section{Experimental Design and Procedure}

We used a pretest-posttest quasi-experimental design to investigate the effects of the different technology-assisted lectures on learning outcomes. Comparisons were drawn between empirical results of learning outcomes corresponding to classroom lectures based on PPT slides and AR tools. We also used interview data to perform a qualitative analysis. After the experiment, the participants' feedback was collected to examine the effects of two different technology-assisted lectures on interactions between the learners and media used in teaching materials.

The experiment was applied to two groups: a PPT lecture group (control group) and AR lecture group (experimental group). The experiment lasted $80 \mathrm{~min}$. The same lesson content, a sixth-grade social science unit titled "History Close to Everyday Life," was used for both groups. The unit is divided into four core subunits: "The 321 Art Alley Settlement," "The Shuidui Village," "Treasure Hill," and "The Morisaka Forestry Village." The experiment was divided into four stages: prior knowledge assessment, experimental intervention, learning achievement assessment and delayed posttesting.

By commencing formal teaching activities, the researchers first described the experimental process to the participants. The participants then completed a $10 \mathrm{~min}$ pretest. After the participants completed the test, equipment operation training was provided for $10 \mathrm{~min}$ to ensure that students of the experimental group could efficiently use the AR tool. As a result, negative effects of technological barriers were avoided as much as possible.

The experimental intervention stage involved the application of formal teaching activities. The instructor taught lessons to students of the experimental and control groups using supplementary materials with two types of 


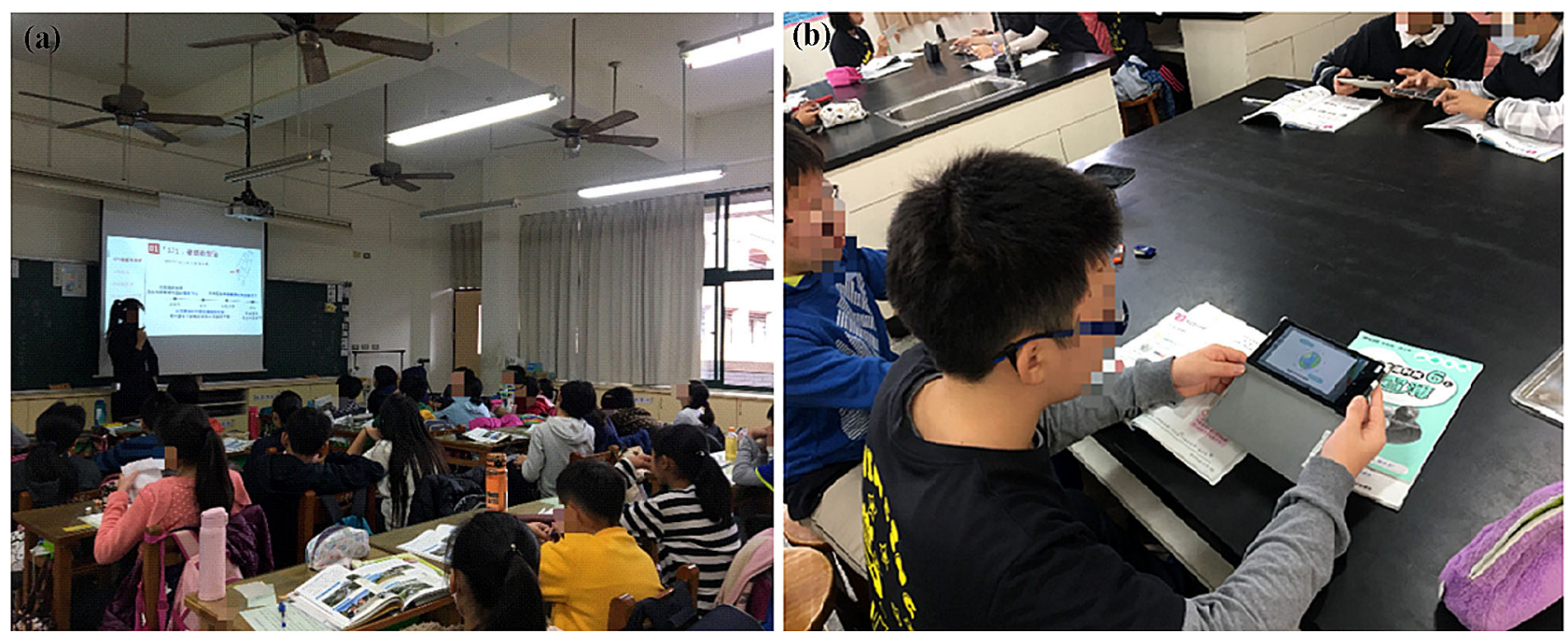

Fig. 1 Students in a classroom a viewing a PPT slide and $\mathbf{b}$ using the AR-assisted tool

Fig. 2 Presentation of supplementary material in a PPT slide

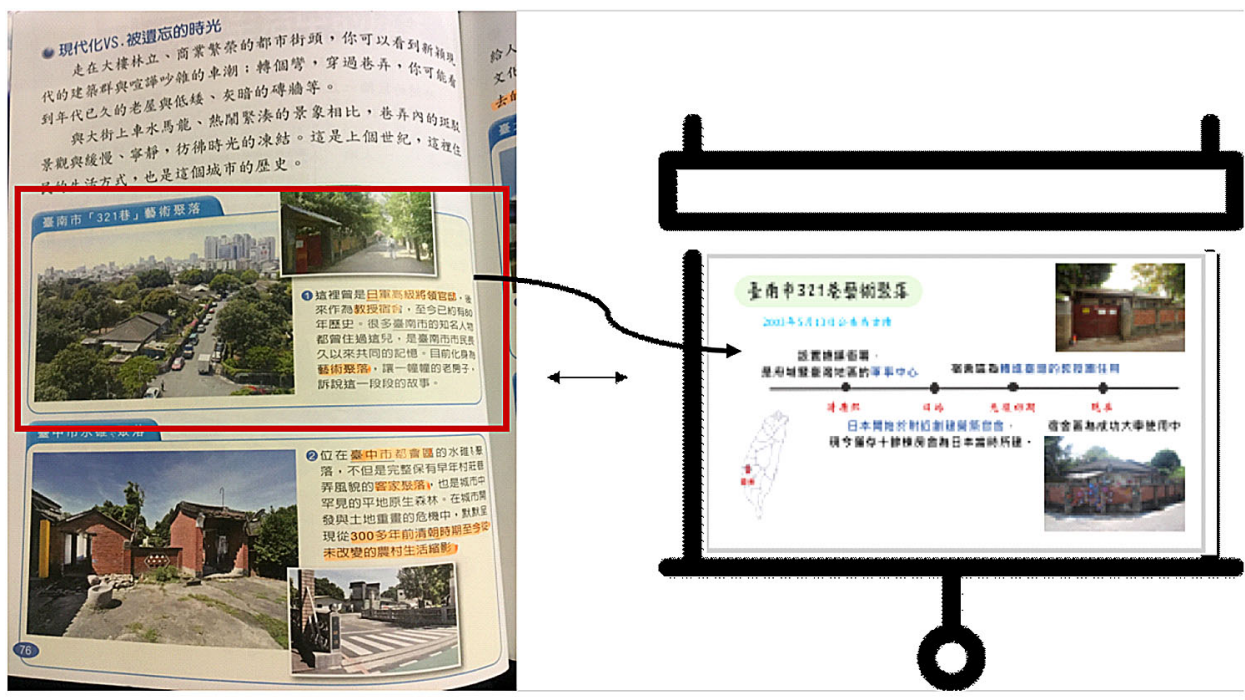

Textbook
Slide technology in combination with a textbook; the lecture lasted $40 \mathrm{~min}$.

In the posttest stage, the participants completed a learning achievement test, which was followed by interviews held between the researchers and five students randomly selected from each group. Two weeks after the formal teaching experiment, a delayed posttest was performed. Questions given through the delayed posttest were the same as those given for the pretest and posttest but with the questions and answers rearranged. The delayed posttest represented the final stage of the experimental study.

\section{Participants}

The study sampled two classes of sixth-grade elementary school students. Each class involved lectures supported with different forms of technological assistance. The effective sample included 52 students; 26 students were included in each group. The lectures were delivered in mixed-ability classrooms, and no participants had previously completed the "History Close to Everyday Life" unit. 
Fig. 3 Example of augmented information presented by the AR tool

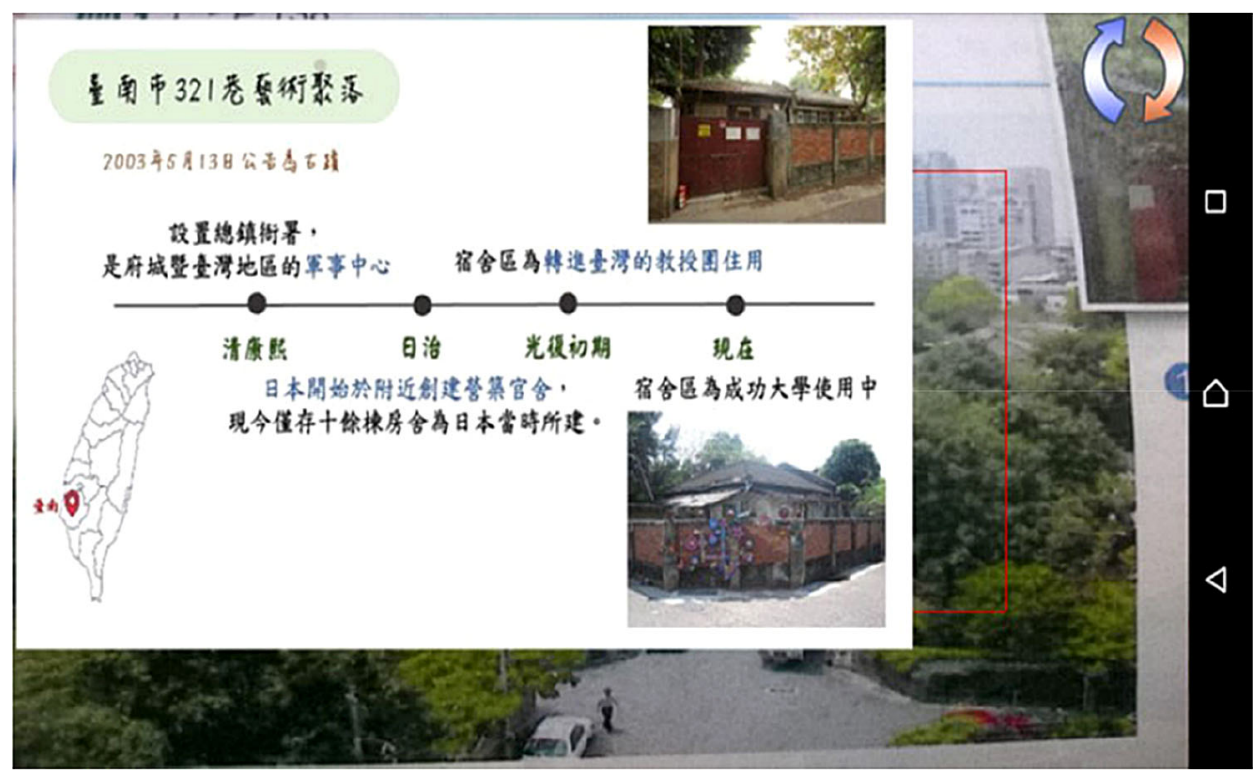

\section{Experimental Tools}

\section{Experimental Equipment}

Students were provided with 6.44-inch Sony Xperia Z Ultra C6802 smartphones equipped with the Android 4.4 operating system. Each mobile phone was $179.4 \mathrm{~mm}$ (length) $\times 92.2 \mathrm{~mm}$ (width) $\times 6.5 \mathrm{~mm}$ (thickness) in size, weighed approximately $212 \mathrm{~g}$ and featured a built-in 8-megapixel camera for AR scanning. Additionally, to ensure the efficient operation of the wireless network during the experiment, two wireless access points were installed in the classroom for use during the experiment.

\section{Tests}

Learning Achievements We used a paper-based pretest and posttest to evaluate learning outcomes and to determine whether the use of AR technologies could effectively improve the students' learning outcomes. The tests included 15 multiple-choice questions ( 1 point per question for a total of 15 points) with four choices provided for each. The test content was designed based on relevant concepts taken from the learning units, and the questions were reviewed by elementary school teachers who served as expert validators of the test.

The pretest and posttest were the same; however, the ordering of questions and answers given in the posttest assessment were randomly adjusted relative to those of the pretest. A pilot test was completed by sixth-grade elementary students who did not participate in the formal experiment. Following a reliability analysis, the internal consistency of questions yielded a Cronbach's alpha value of .738 .
Interviews To understand how the learners interacted with the instructional media during the experiment, students from the two groups were randomly selected for interviews after the experiment. During the interviews, the interviewers used neutral language and encouraged the interviewees to express their thoughts on their learning experiences during the experiment to avoid interfering with the participants' responses.

\section{Results}

\section{Learning Achievements}

The pretest and posttest results were used to analyze the effects of technology-assisted lectures on learning outcomes. Table 1 presents the pretest and posttest mean and standard deviation of scores for each group.

To eliminate individual variations in the prior knowledge of each group, a one-way ANCOVA was used first to exclude the pretest scores of each group and to then verify differences in learning outcomes of the two groups.

Before conducting the ANCOVA, a test of the homogeneity of regression slopes was performed to confirm that differences did not exist between the covariate variable (pretest scores) and dependent variable (posttest scores). Homogeneity test results of the regression coefficients for each group were measured as $F(1,48)=.001$, $p=.978>.05$, not reaching a the .05 significance level. Thus, the pretest and posttest scores for each group show a consistent linear relationship, and an ANCOVA was thus subsequently performed.

The results of the ANCOVA, $F(1,49)=17.234$, $p=.000<.001$, reached significance, showing that after 
Table 1 Pretest and posttest mean and standard deviation of the learning achievement

\begin{tabular}{lllcr}
\hline Test & Group & Number of participants & Mean & Standard deviation \\
\hline Pretest scores & PPT lecture & 26 & 6.69 & 2.40 \\
& AR lecture & 26 & 6.65 & 1.38 \\
Posttest scores & PPT lecture & 26 & 10.15 & 2.78 \\
& AR lecture & 26 & 12.77 & 2.01 \\
\hline
\end{tabular}

excluding effects of the pretest scores, the two technologyassisted lectures significantly affected the participants' learning outcomes. A post hoc comparison of the adjusted means shows that the AR lecture group $(M=12.778)$ performed better than the PPT lectured group $(M=10.145)$.

\section{Delayed Posttest}

The delayed posttest was performed two weeks after the experiment to assess the learners' retention of the course content. Table 2 presents the means and standard deviations of the posttest and delayed posttest scores for each group. A one-way ANCOVA was used to test differences in the learners' levels of retention across two lecturing approaches. Prior to performing the ANCOVA, a test of the homogeneity of regression slopes was performed to determine whether differences existed between the covariate variable (pretest scores) and dependent variable (delayed posttest scores). The homogeneity test results of the regression coefficients for each group, $F(1,48)=.045$, $p=.834>.05$, did not reach a .05 significance level, showing that the pretest and delayed posttest scores of each group show a consistent linear relationship. The ANCOVA was then performed.

The results of the ANCOVA, $F(1,49)=5.877$, $p=.019<.05$, reached significance and demonstrate that after excluding the effect of pretest scores, the two lecturing approaches significantly affected the learners' levels of retention. A post hoc comparison of adjusted means shows that the AR lecture group $(M=12.348)$ performed better than the PPT lecture group $(M=10.460)$.

\section{Interview Feedback}

To understand the differences in students' interactions with the textbooks and AR handheld devices or PPT slides, five students were randomly selected from each group and interviewed. Interview records were analyzed to determine interactions and their causes. The following question was asked during the interviews: "During a lecture, do you pay more attention to the content of handheld devices (or slides) or to the textbook? Why?" The results of the analysis indicate that students from the AR lecture group first read the textbook content and then focused on the handheld device. In other words, the students focused on one medium of teaching material (textbook or handheld) at a time. For the PPT lecture group, however, students alternated their attention between two forms of teaching material during the lecture; they read the textbook while viewing the computer slides. These results are consistent with the study's hypothesis that the use of AR while integrating related teaching materials can prevent learners from expending excessive cognitive resources on shifting their focus between instructional media.

When students from the PPT lecture group reviewed the textbook content, they divided their attention between the instructional media. This division of attention derived from the interview analysis may be attributed to the following:

1. To understand concepts presented in the textbook, students must compare content from the textbook and slides.

2. Slides may contain information that can be used to answer questions included in the textbook.

3. The textbook only includes pictures whereas the slides include animations.

4. Both the textbook and slides present unique content and key points that must be learned.

Table 2 Mean and standard deviation of posttest scores and delayed posttest scores

\begin{tabular}{lllll}
\hline Group & Test & Number of participants & Mean & Standard deviation \\
\hline PPT lecture & Posttest & 26 & 10.15 & 2.78 \\
& Delayed posttest & 26 & 10.46 & 3.01 \\
AR lecture & Posttest & 26 & 12.77 & 2.01 \\
& Delayed posttest & 26 & 12.35 & 2.54 \\
\hline
\end{tabular}


5. The slides provide more interesting supplementary materials that can enhance students' understanding of the textbook content.

In comparison, students from the AR lecture group focused their attention on a single teaching medium during their learning process. The use of handheld devices to scan textbook content facilitated the students' concentration, and the AR overlay reduced the spatial distance between the two types of media. In addition to these two key factors, other possible causes of learning outcomes derived from the interview analysis include the following:

1. The handheld device presents videos or animations that are more interesting than the textbook and that can facilitate students' understanding of concepts listed in the textbook.

2. Students can listen to the teacher while viewing the handheld device.

3. It is unnecessary for students to continually watch the blackboard or copy material from the blackboard.

4. Students can operate handheld devices independently.

5. When students cannot understand the content presented, they can repeatedly view it until they understand it.

6. The use of AR to supplement teaching materials is more convenient for students and helps them learn.

7. When AR is used, most supplementary content is not given in the textbook.

8. Using AR for the first time is refreshing, and AR can excite students' interest.

9. AR content can be organized to help students more fully understand key concepts presented in textbook content.

\section{Discussion}

The experimental results show that among students studied with no notable differences in prior knowledge, the learning outcomes of both student groups were significantly improved; thus, the teaching experiment served as an effective learning activity for both groups. Pretest scores for the AR lecture group were found to be lower than those of the PPT lecture group, but posttest scores of the AR lecture group were significantly higher than those of the PPT lecture group. Furthermore, an analysis of the delayed test results shows that the learning retention outcomes of the two groups differed significantly. This result shows that the integration of AR with textbook content benefited the students' levels of learning retention. This finding is consistent with those of other studies showing that AR facilitates knowledge retention effect (Ibáñez et al. 2014).
According to our interview data, students of the AR lecture group preferred the integration of textbook content with AR (i.e., the integration of textbooks and augmentation within the same visual range), as this prevented them from needing to search through related teaching materials from two different physical locations. This result supports the spatial contiguity principle (Mayer 2001), which is violated when using PPT presentations (DuFrene and Lehman 2004; Jordan and Papp 2014; Tufte 2003). Students of the PPT lecture group were unable to place the textbook content and slide augmentations within the same visual range during the instructional process, disrupting their concentration and reducing the frequency of teacherstudent interactions and the number of discussion opportunities in classroom lectures (Jordan and Papp 2014). As concluded by Ahmadi et al. (2007) and Hill et al. (2012), distractions resulting from the spreading of content across two media sources can result in the neglect of essential content and can affect learning outcomes.

In addition to satisfying the spatial contiguity principle, the AR course lecture satisfied the temporal contiguity principle (i.e., augmentation is presented on the AR device screen when the AR device is used to scan learning objects from the textbook during a lecture, satisfying the temporal contiguity principle). Related studies have suggested that the cognitive theory of multimedia learning can be applied to presentation design to improve PPT course lecturing effects (Berk 2011; Grech 2018; Jordan and Papp 2014; Nagmoti 2017; Pate and Posey 2016). However, this effect may not be significantly improved, as PPT course lecturing cannot be integrated with textbook teaching, resulting in the temporal and spatial contiguity principles not being satisfied.

According to the above findings and to some related studies (Huang et al. 2016; Zhang et al. 2015; FerrerTorregrosa et al. 2015), the virtual features of AR allow augmented messages to be used as augmentations and to be superimposed on an original textbook, resulting in superior instructional outcomes. Our posttest and delayed test scores emphasize that teaching materials should be superimposed onto each other and be presented in a similar position to enhance knowledge transfer and to reduce the cognitive load on students (Moreno and Mayer 1999). The findings also verify that AR integration and superimposition functions can affect learning outcomes. Ozcelik and Acarturk (2011) maintained that when temporal and spatial distances between related information presentations can be reduced, students' external cognitive loads are alleviated, enhancing learning. The results of this study respond to related studies seeking to explain how AR improves learning outcomes using the cognitive theory of multimedia learning (Sommerauer and Müller 2014; Akçayır et al. 2016). 


\section{Conclusion}

To facilitate learning, technology-assisted devices and textbooks must be integrated, and the elements of emphasis, augmentation, and integration must be applied to the teaching process. However, computer presentation alone is unable to provide these elements. Therefore, this study used AR scanning and virtual integration functions to establish a tool for AR-assisted lecturing that integrates these three elements. To determine the effect of AR course lecturing on students' learning outcomes, we employed a quasi-experimental research method and found the AR lecture group to achieve notably higher posttest scores than the PPT lecture group. A similar result was obtained from the delayed test. In interviewing the student participants, it was found that the students enjoyed the AR-assisted lecture. Students were able to concentrate heavily on the learning content, and they noticed the textbook content as well. Moreover, the augmentation function of the AR tool enabled the students to view textbook content and multimedia augmentations simultaneously.

In addition to achieving emphasis, augmentation, and integration in AR course teaching that connects technology-assisted devices with textbooks in classroom lectures, the AR presentation method satisfies temporal and spatial contiguity principles of multimedia learning cognitive theory. Timely presentation and superposition applied after AR scanning is impossible to achieve with computer presentations alone. Approaches that satisfy all principles of multimedia learning cognitive theory should be developed in the future to further enhance teaching effects.

Open Access This article is licensed under a Creative Commons Attribution 4.0 International License, which permits use, sharing, adaptation, distribution and reproduction in any medium or format, as long as you give appropriate credit to the original author(s) and the source, provide a link to the Creative Commons licence, and indicate if changes were made. The images or other third party material in this article are included in the article's Creative Commons licence, unless indicated otherwise in a credit line to the material. If material is not included in the article's Creative Commons licence and your intended use is not permitted by statutory regulation or exceeds the permitted use, you will need to obtain permission directly from the copyright holder. To view a copy of this licence, visit http://creativecommons.org/licenses/by/4.0/.

Funding The work was supported by the National Science Council, Taiwan, Republic of China [Grant Numbers MOST 107-2511-H-003027-MY3] and the "Institute for Research Excellence in Learning Sciences" of National Taiwan Normal University (NTNU) from The Featured Areas Research Center Program within the framework of the Higher Education Sprout Project by the Ministry of Education in Taiwan.

\section{References}

Ahmadi, M., Dileepan, P., \& Raiszadeh, F. (2007). Is PowerPoint evil? Students' perceptions. Review of Business Research, 7(4), $15-19$.

Akçayır, M., \& Akçayır, G. (2017). Advantages and challenges associated with augmented reality for education: A systematic review of the literature. Educational Research Review, 20, 1-11.

Akçayır, M., Akçayır, G., Pektaş, H. M., \& Ocak, M. A. (2016). Augmented reality in science laboratories: The effects of augmented reality on university students' laboratory skills and attitudes toward science laboratories. Computers in Human Behavior, 57, 334-342.

Akhlaghi, M., \& Zareian, G. (2015). The effect of PowerPoint presentation on grammar and vocabulary learning of Iranian preuniversity EFL learners. Academic Research International, 6, $160-165$.

Apperson, J. M., Laws, E. L., \& Scepansky, J. A. (2006). The impact of presentation graphics on students' experiences in the classroom. Computers \& Education, 47, 116-126.

Baker, J. P., Goodboy, A. K., Bowman, N. D., \& Wright, A. A. (2018). Does teaching with PowerPoint increase students' learning? A meta-analysis. Computers \& Education, 126, 376-387.

Bamne, S. N., \& Bamne, A. S. (2016). Comparative study of chalkboard teaching over PowerPoint teaching as a teaching tool in undergraduate medical teaching. International Journal of Medical Science and Public Health, 5, 2585-2587.

Bartlett, R. M., \& Strough, J. (2003). Multimedia versus tradition course instructions in introductory social psychology. Teaching of Psychology, 30, 335-338.

Bartsch, R. A., \& Cobern, K. M. (2003). Effectiveness of PowerPoint presentation in lectures. Computers \& Education, 41, 77-86.

Berk, R. A. (2011). Research on PowerPoint: From basic features to multimedia. International Journal of Technology in Teaching and Learning, 7(1), 24-35.

Berney, S., \& Betrancourt, M. (2016). Does animation enhance learning? A meta-analysis. Computers \& Education, 101, $150-167$.

Chang, H. Y., Hsu, Y. S., Wu, H. K., \& Tsai, C. C. (2018). Students' development of socio-scientific reasoning in a mobile augmented reality learning environment. International Journal of Science Education, 40(12), 1410-1431.

Chang, K. E., Chang, C. T., Hou, H. T., Sung, Y. T., Chao, H. L., \& Lee, C. M. (2014). Development and behavioral pattern analysis of a mobile guide system with augmented reality for painting appreciation instruction in an art museum. Computers \& Education, 71, 185-197.

Chang, K. E., Zhang, J., Huang, Y. S., Liu, T. C., \& Sung, Y. T., (2019). Applying AR in physical education on motor skills learning. Interactive Learning Environment (in press).

Chang, S. C., \& Hwang, G. J. (2018). Impacts of an augmented reality-based flipped learning guiding approach on students' scientific project performance and perceptions. Computers \& Education, 125, 226-239.

Chang, Y. L., Hou, H. T., Pan, C. Y., Sung, Y. T., \& Chang, K. E. (2015). Apply an augmented reality in a mobile guidance to increase sense of place for heritage places. Educational Technology \& Society, 18(2), 166-178.

Chao, K. H., Chang, K. E., Lan, C. H., Kinshuk, \& Sung, Y. T. (2016). Integration of mobile AR technology in performance assessment. Educational Technology \& Society, 19(4), 239-251.

Chao, K. H., Lan, C. H., Kinshuk, K. E., \& Sung, Y. T. (2014). Implementation of a mobile peer assessment system with augmented reality in a fundamental design course. Knowledge 
Management \& E-Learning: An International Journal, 6(2), 123-139.

Cheng, K. H., \& Tsai, C. C. (2014). Children and parents' reading of an augmented reality picture book: Analyses of behavioral patterns and cognitive attainment. Computers \& Education, 72, 302-312.

Dean, T., Lee-Post, A., \& Hapke, H. (2016). Universal design for learning in teaching large lecture classes. Journal of Marketing Education, 39, 5-16.

Debevec, K., Shih, M., \& Kashyap, V. (2006). Learning strategies and performance in a technology integrated classroom. Journal of Research on Technology in Education, 38(3), 293-307.

DuFrene, D. D., \& Lehman, C. M. (2004). Concept, content, construction and contingencies: Getting the horse before the PowerPoint cart. Business Communication Quarterly, 67, 84-88.

Ferrer-Torregrosa, J., Torralba, J., Jimenez, M. A., García, S., \& Barcia, J. M. (2015). ARBOOK: Development and assessment of a tool based on augmented reality for anatomy. Journal of Science Education and Technology, 24(1), 119-124.

Gervautz, M., \& Schmalstieg, D. (2012). Anywhere interfaces using handheld augmented reality. Computer, 45(7), 26-31.

Gier, V. S., \& Kreiner, D. S. (2009). Incorporating active learning with PowerPoint-based lectures using content-based questions. Teaching of Psychology, 36, 134-139.

Grech, V. (2018). The application of the Mayer multimedia learning theory to medical PowerPoint slide show presentations. Journal of Visual Communication in Medicine, 41, 36-41.

Hallett, T. L., \& Faria, G. (2006). Teaching with multimedia: Do bells and whistles help students learn? Journal of Technology in Human Services, 24, 167-179.

Hallewell, M. J., \& Lackovic, N. (2017). Do pictures 'tell' a thousand words in lectures? How lecturers vocalize photographs in their presentations. Higher Education Research and Development, 36, $1166-1180$.

Hill, A., Arford, T., Lubitow, A., \& Smollin, L. M. (2012). "I'm Ambivalent about It": The dilemmas of PowerPoint. Teaching Sociology, 40(3), 242-256.

Hsiao, H., Chang, C., Lin, C., \& Wang, Y. (2013). Weather observers: A manipulative augmented reality system for weather simulations at home, in the classroom, and at a museum. Interactive Learning Environments, 24(1), 205-223.

Huang, Y. R., Zhang, J., Liu, T. C., Sung, Y. T., Chang, K. E., \& Yang, M. J. (2016). AR-based learning and AR guides as strategy in two-phase learning enhancement: A case study. In Mixed and Augmented Reality (ISMAR-Adjunct), IEEE International Symposium (pp. 318-321).

Ibáñez, M., \& Carlos, D. (2018). Augmented reality for STEM learning: A systematic review. Computer \& Education, 123, 109-123.

Ibáñez, M., Di Serio, Á., Villarán, D., \& Delgado Kloos, C. (2014). Experimenting with electromagnetism using augmented reality: Impact on flow student experience and educational effectiveness. Computers \& Education, 71, 1-13.

Jalali, S., \& Talebi, H. (2014). The effect of PowerPoint presentations on EFL learners' performance and attitude. Social Sciences and Humanities, 22, 1147-1161.

James, K. E., Burke, L. A., \& Hutchins, H. M. (2006). Powerful or pointless? Faculty versus student perceptions of PowerPoint use in business education. Business Communication Quarterly, 69(4), 374-396.

Jordan, L. A., \& Papp, R. (2014). PowerPoint ${ }^{\circledR}$ : It's not “yes" or "no": It's "when" and "how". Research in Higher Education Journal, 22, 1-11.

Johnson, D. A., \& Christensen, J. (2011). A comparison of simplifiedvisually rich and traditional presentation styles. Teaching of Psychology, 38, 293-297.
Kim, H. (2018). Impact of slide-based lectures on undergraduate students' learning: Mixed effects of accessibility to slides, differences in note-taking, and memory term. Computers \& Education, 123, 13-25.

Ledbetter, A. M., \& Finn, A. N. (2018). Perceived teacher credibility and students' affect as a function of instructors' use of PowerPoint and email. Communication Education, 67, 31-51.

Levasseur, D. G., \& Sawyer, K. (2006). Pedagogy meets PowerPoint: A research review of the effects of computer-generated slides in the classroom. Review of Communication, 6, 101-123.

Lowry, R. B. (1999). Electronic presentation of lectures: Effect upon student performance. University Chemistry Education, 3, 18-21.

Mantei, E. J. (2000). Using internet class notes and PowerPoint in physical geology lecture: Comparing the success of computer technology with traditional teaching techniques. Journal of College Science Teaching, 29(2000), 301-305.

Mayer, R. E. (2001). What good is educational psychology? The case of cognition and instruction. Educational Psychologist, 36(2), 83-88.

Mayer, R. E. (2014). The Cambridge handbook of multimedia learning. Cambribge: Cambridge University Press.

Mayer, R. E. (2017). Using multimedia for e-learning. Journal of Computer-Assisted Learning, 33(5), 403-423.

Mayer, R. E., \& Moreno, R. (2002). Aids to computer-based multimedia learning. Learning and instruction, 12(1), 107-119.

Miller, S. T., \& James, R. C. (2011). The effect of animations within PowerPoint presentations on learning introductory astronomy. Astronomy Education Review, 10, 1-13.

Moreno, R., \& Mayer, R. E. (1999). Cognitive principles of multimedia learning: The role of modality and contiguity. Journal of Educational Psychology, 91(2), 358-368.

Nagmoti, J. M. (2017). Departing from PowerPoint default mode: Applying Mayer's multimedia principles for enhanced learning of parasitology. Indian Journal of Medical Microbiology, 35(2), 199-203.

Nouri, H., \& Shahid, A. (2005). The effect of PowerPoint presentations on student learning and attitudes. Global Perspectives on Accounting Education, 2, 53-73.

Ozcelik, E., \& Acarturk, C. (2011). Reducing the spatial distance between printed and online information sources by means of mobile technology enhances learning: Using 2D barcodes. Computers \& Education, 57(3), 2077-2085.

Pate, A., \& Posey, S. (2016). Effects of applying multimedia design principles in PowerPoint lecture redesign. Currents in Pharmacy Teaching and Learning, 8, 235-239.

Penciner, R. (2013). Does PowerPoint enhance learning? Canadian Journal of Emergency Medicine, 15(2), 109-112.

Pros, R. C., Tarrida, A. C., Martin, M. M. B., \& Amores, M. C. C. (2013). Effects of the methodology on content learning. Intangible Capital, 9, 184-198.

Rick, P. (2012). Does PowerPoint enhance learning? Canadian Journal of Emergency Medicine., 15(2), 109-112.

Rickman, J., \& Grudzinski, M. (2000). Student expectations of information technology use in the classroom. Educause Quarterly, 23(1), 24-30.

Savoy, A., Proctor, R. W., \& Salvendy, G. (2009). Information retention from PowerPoint ${ }^{\mathrm{TM}}$ and traditional lectures. Computers \& Education, 52, 858-867.

Schnettler, B. (2006). Orchestrating bullet lists and commentaries: a video performance analysis of computer supported presentations. In H. Knoblauch, et al. (Eds.), Video analysis: methodology and methods qualitative audiovisual data analysis in sociology (pp. 155-168). Frankfurt am Main and New York: Lang.

Seth, V., Upadhyaya, P., Ahmad, M., \& Kumar, V. (2010). Impact of various lecture delivery methods in pharmacology. EXCLI Journal, 9, 96-101. 
Shapiro, E. L., Kerssen-Griep, J., Gayle, B. M., \& Allen, M. (2006). How powerful is PowerPoint? Analyzing the educational effects of desktop presentational programs in the classroom. In B. M. Gayle, R. W. Preiss, N. Burrell, \& M. Allen (Eds.), Classroom communication and instructional processes: Advances through meta-analysis (pp. 61-75). New York, NY: Routledge.

Sommerauer, P., \& Müller, O. (2014). Augmented reality in informal learning environments: A field experiment in a mathematics exhibition. Computers \& Education, 79, 59-68.

Sugahara, S., \& Boland, G. (2006). The effectiveness of PowerPoint presentations in the accounting classroom. Accounting Education: International Journal, 15, 391-403.

Szabo, A., \& Hastings, N. (2000). Using IT in the undergraduate classroom: Should we replace the blackboard with PowerPoint. Computers \& Education, 35, 175-187.

Tangen, J. M., Constable, M. D., Durrant, E., Teeter, C., Beston, B. R., \& Kim, J. A. (2011). The role of interest and images in slideware presentations. Computers \& Education, 56, 865-872.

Tufte, E. (2003). The cognitive style of PowerPoint. Cheshire, CT: Graphics Press.

Valdez, A. (2013). Multimedia learning from PowerPoint: Use of adjunct questions. Psychology Journal, 10, 35-44.

Waheeda, S., \& Murthy, S. K. (2015). A comparative study of blackboard teaching with PowerPoint teaching in 1 year medical students. National Journal of Basic Medical Sciences, 6, 11-13.
Wecker, C. (2012). Slide presentation as speech suppressors: When and why learners miss oral information. Computers \& Education, 59, 260-273.

Williams, R. L., \& Eggert, A. C. (2002). Notetaking in college classes: Student patterns and instructional strategies. The Journal of General Education, 51(3), 173-199.

Zhang, J., Hou, H. T., \& Chang, K. E. (2012). Designing a streamlined viewport strategy system to enhance performance in context awareness in mobile learning environments. In $\mathrm{Ad}$ vanced Applied Informatics (IIAIAAI), 2012 IIAI International Conference (pp. 72-76). IEEE.

Zhang, J., Liu, T. C., Sung, Y. T., \& Chang, K. E. (2015). Using augmented reality to promote homogeneity in learning achievement. In Mixed and Augmented Reality-Media, Art, Social Science, Humanities and Design (ISMAR-MASH'D), 2015 IEEE International Symposium (pp. 1-5).

Zhang, J., Sung, Y., Hou, H., \& Chang, K. (2014). The development and evaluation of an augmented reality-based armillary sphere for astronomical observation instruction. Computers \& Education, 73, 178-188.

Publisher's Note Springer Nature remains neutral with regard to jurisdictional claims in published maps and institutional affiliations. 